\title{
TIM ELMER: 'IN THE ARMED FORCES WE LOSE THOUSANDS OF MAN HOURS EACH YEAR TO PEOPLE LEAVING TO HAVE DENTAL CARE DELIVERED.'
}

Tim Elmer talks to the $B D J$ about life in the Defence Dental Services, providing care on the frontline and the impact of dental disease on the Armed Forces

\section{Why did you choose to study dentistry?}

The truth of why I went into dentistry isn't based on some great calling or any particular experience I had. I went to the King's grammar school in Grantham and if I'm honest my best friend at the time suggested doing dentistry, so I said I'd do that as well. But I got the grades and he didn't. I turned up on day one and thought I'd see what it was like and it fitted me well so I progressed with it. It was random and chance, but I'm much more of a fatalist than someone who sits down with a three-year plan.

\section{What attracted you to the Royal Navy?}

There were a number of reasons. I was thinking about my options in the fourth year of dental school and had started work at a transitional training unit, which Sheffield University was quite avant-garde in having - it was effectively a practice set up where you'd go in and, instead of the really close, overthe-shoulder supervision, you'd more or less be practising on your own. I kind of enjoyed it and I kind of didn't like it at all. Although no money exchanged hands, the financial aspect didn't float my boat; I just enjoyed delivering the healthcare. I grew up in Lincolnshire, pretty far from the sea, so I had a desire to "see the world'. A Navy careers officer came to Sheffield and played a
'The real challenge is meeting the dental needs of your patients so that they can do their job'

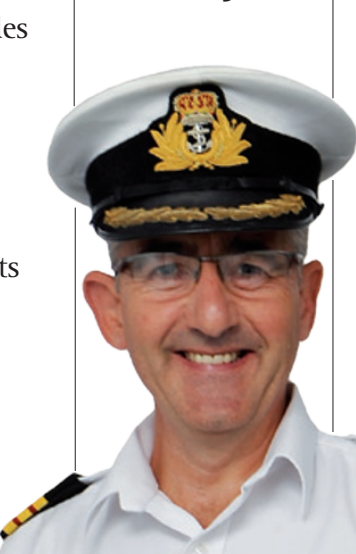
for that high street dentistry great for some and a hugely laudable endeavour but definitely not for me; re-joined the Navy and kept on going with it.

This year is the centenary of the start of the First World War, how do dental problems of current military forces compare?

In terms of the diseases military personnel suffered it was exactly the same; the caries, periodontal disease and even battle trauma injuries would have been common to the dental surgeons in the First World War as they are today, though there may be a difference in severity or prevalence. That said, interestingly there wasn't a constituted army dental corps or naval service at the start of the First World War and the RAF didn't form until April 1918. It was during the Battle of the Aisne in October 1914 that the Commander of the First

ABOUT TIM
Tim Elmer is Surgeon Commander
in the Defence Dental Services
and Consultant in Dental Public
Health. Joining the Royal Navy
in 1988 after qualifying from
Sheffield Dental Hospital, Tim
has served around the world, on
loan service with the Sultan of
Brunei's Army and completed tours
in Gibraltar and HMS Invincible.
Tim has undertaken higher
professional training in dental
public health, becoming accredited
as a consultant in September
2013. During his time in the Navy,
Tim has faced some unexpected
challenges, such as helping to treat
servicemen injured by aircraft
carrier machinery in addition to
those with toothache.

Army suffered severe toothache and there was nobody to treat him. He made a request to the War Office that said they must have dental surgeons operating. They weren't conscripted as such and actually it was civilian practitioners who carried out most of the treatment of UK soldiers and were employed by the Army. After a series of evolutions, an admiral had toothache and was treated by a civilian dentist who told him that his medical colleagues received a commission in the Royal Naval Reserve and it was felt that it should also be so for dentists. So in 1917 the Royal Army Dental Corps and Royal Naval Dental Service came into being as a result of the requirement to provide primary dental care to troops on land operations and in the maritime environment.

\section{How have military health systems changed in this time?}

There has been an enduring need to provide both primary and secondary healthcare services both at home, on operations and at sea. By the end of the First World War there were 850 dental surgeons serving with the Army, so it had gone from nothing to quite a big operation. The scale of these operations waxes and wanes but in terms of constants for the troops that receive the care it's still free at point of delivery and always has been; it's provided by 
a salaried dental service so money doesn't change hands. In terms of structural changes what we do differently now are things like the casualty evacuation system. The casevac system in Afghanistan is a good example - someone who is injured in Afghanistan can be back at the Queen Elizabeth Hospital in Birmingham in less than 24 hours. That is a very, very different set of operating parameters to how things were in the First World War. In structural terms in the First World War there was very clearly the Army, the Navy and later the Air Force, and whilst we've still got the three single services, the command structure for the dental services has been amalgamated into one triservice organisation.

\section{How important is the role of the dental team within the defence services?}

Dental diseases are still really common and however much we try, there will always be this enduring, rolling population of people experiencing dental problems. In terms of how important they are in the defence services, I've often thought it's one of those services that you'd really notice if you took it away and I'm sure many of my general practice colleagues in the Services would agree with me. The point at which we intervene to deliver treatment is often before the patient has experienced any pain. You do all this work that does an enormous amount of good at stopping the disease process in its tracks but without much fanfare. If you think about the number of people who actually make the effort to cross hostile terrain to get to the dental service, it's clearly desperately important to them. We do a continuous attitude survey in the Armed Forces that asks the people who participate what the top five things are that make them want to stay in the Armed Forces, the retention factors, and results from the last survey put the top reason as dental provision - above the pensions, leave and medical care. Within the Dental Defence Services we also run our own customer satisfaction survey across a stratified sample of foreign bases and at home. Over 3,500 patients returned their survey, with an overall satisfaction of $97.5 \%$ with the service delivered. I think we're doing something right there.

\section{What are the challenges of working within the Defence Dental Services and providing dental care on the front line?}

I think it depends what you mean by on the front line. The front line can be in a tent in a dusty, hostile environment or it could be in a ship, in a maritime environment. We don't do any dentistry up in the air, so it's either a land base or sea. Each environment brings its own challenge, whether one is working with a portable dental unit that has been helicoptered in or trying to treat people below decks in a ship that's rolling in a heavy sea - I've spent hours and hours on board ship, quite literally bungeed to the chair and operating unit, because when you're at sea everything is moving. You could also be quite literally in a tent, with a limited or patchy intermittent energy supply that allows you to drive your kit, and sometimes that shapes the treatment you can deliver - so if your remit is to get rid of the pain and they need an extraction then that's perhaps what they'll get, whereas in a different environment that might not be the choice that the patient would actually make or would be the choice that you would want the patient to make. The real challenge is meeting the dental needs of your patients so that they can go and do their job. If the patient you see is about to embark on patrol in some hostile foreign country then the dentistry provided has to have, as far as is possible, a predictable outcome.

\section{Does oral health have a big impact on the performance of UK forces?}

We know from data collected on operations that dental problems are usually in the top five of 'disease non-battle injuries' (DNBI), which cause service personnel to present for treatment. The data we've collected from Operation Herrick would suggest that we can lose thousands of man hours each year to people having to leave their primary operational role to have dental care delivered.

I think that good oral health has an extraordinarily positive impact because it allows people to go and do their operational duty and not be worried that something's going to flare up. I think by the same token, poor oral health can have a significant impact. For an individual in a forward operating base, the journey back to the dental service may mean transit through a hostile environment, it may mean the use of transport assets with risk to them, and their removal from a small team may mean a critical operating gap.

\section{How can dental disease non-battle injuries be reduced?}

Reducing DNBI is the entire raison d'etre for military dental services and broadly speaking there are two main areas of activity: number one is to actively treat the disease that we see in new recruits to try and stop any disease process. I haven't mastered time travel and can't send them back into a different world to prevent the disease, but once we've got them, we'll look after them. We have a number of active strands, including active oral health promotion for recruits, "brush twice a day; spit, don't rinse' and an active fluoride varnish application programme. We're trying to make it a normal part of daily life because actually it's fairly straightforward: if you can prevent the disease,

you won't get the disease nonbattle injury. It's really difficult to predict when a traumatic event will happen, like if somebody slams the brakes on a land rover and someone's face smacks into a piece of metal work - that's an unpredictable accident and I'm not going to suggest that all our soldiers wear gum shields during their daily work. But once we've treated the recruits, everybody who comes back for their periodic dental inspection gets an assessment of their caries risk - there's this continuous iterative process where if we think their caries risk has changed then we will give them oral health education, fluoride varnish, prescribe high fluoride toothpaste - everything you would expect from Delivering better oral health. Recuits to the Armed Forces have a strict routine under training. For instance, they have to clean their boots every day and shave every day, so they should also brush their teeth - it's about normalising the activity.

\section{How does the oral health of the British Armed Forces, Royal Navy and Royal Air Force compare to that of the general public?}

We don't measure oral health in the same way as the Adult Dental Health Survey and the NHS Dental Epidemiology programme, which measure oral health according to a particular set of diagnostic parameters in a particular standardised way. The ADHS is a visual examination performed in the participant's home, whereas all our recruits are assessed on entry in a dental surgery with bitewing radiographs, so you get a different yield. The case-mix in terms of age and gender in the Armed Forces is unlike the general population and there are also differences in the oral health of recruits to each of the services, which research shows is linked to different socio-demographic profiles that each service recruit from. 


\section{Have there been any developments in general dental care that have arisen directly from advances within military dental practice?}

When you look at advances in surgery, Sir William Kelsey Fry and Sir Harold Gillies in the First World War were Army maxillofacial surgeons who did an enormous amount of work in treating gunshot wounds and doing facial reconstructions and were very much pioneers. When I think of some of the incredible diagnostic facilities in theatre at places like Camp Bastion and some of the presentations I've been to where they show you a $360^{\circ}$ MRI scan of somebody's face who has received a gunshot wound and they've managed to put back together an explosion of fragments, that to me is out of this world.

But battle trauma is not nearly as common as car crash trauma to the face so the motorcar and motorcycle probably drove much greater degrees of research and evolution of the surgical processes than that of gunshot wounds.

\section{What do you feel would make the biggest positive impact on dental public health?}

I think for the Armed Forces we're already doing it, in that we have an oral health strategy that is focused on prevention, delivering treatment at the right time to the right people in the right place and seeking to reduce the disease burden.

I remain convinced of the safety and an enduring degree of benefit from the fluoridation of public water supplies, as it is a population-based approach to try and give everybody the best oral health. I can't fluoridate the water supply for the Armed Forces, it's just not practicable, but I think it is beneficial for the general public, which in turn would have an impact for people joining the Armed Forces, as anything we can do to reduce the disease burden before they get to the Armed Forces will help.

I've just published an article $(\mathrm{Br}$ Dent J 2014; 216: E10) on an ecological study on water fluoridation comparing the North West and West Midlands - both areas with deprivation and relative affluence but wildly different extraction rates in hospitals.

'Dentistry
problems are
usually in
the top five
of disease
non-battle
injuries.'

Why would that be? There is a much greater rate of admission to hospital in 0-19-year-olds for the extraction of teeth in non-fluoridated areas. Whether or not the impact of water fluoridation is as great at it would have been in the times before we had fluoridated toothpaste is a completely different debate.

\section{What has been the most challenging location you have worked in?}

Without any shadow of a doubt, it's in an aircraft carrier, 200 miles due west of the Outer Hebrides in a Force 9 gale. The aircraft carrier was $17 \mathrm{~m}$ from the water line to the flight deck, and waves were coming over that and there were moments when it felt like you were in an anti-gravity environment. We operated for a while and it's the one time when I've had to say it is no longer safe to perform. An aircraft carrier is quite a big ship and it's the one night I remember having to strap myself to my bunk to stop myself from falling out. It was a special experience though and it goes back to why I joined the Navy. I'm absolutely, totally committed to the Navy and for me serving at sea and looking after sailors in their natural maritime environment is the best dental job on God's green earth.

\section{What has been your proudest career moment to date?}

I tend to experience pride when I see people I've helped doing well. One of my ex-foundation dentists has done brilliantly - he's finished his foundation training, got his green beret with the Royal Marines and is now a successful practitioner in Exeter - and I'm proud as punch that the tangential interaction I had on his life for that year has actually formed part of his practising life. If you pushed me really hard to be immodest then I received the Harvey Fletcher Award from the Royal Naval Dental Services, which would be pretty high on my list. The $B D J$ covered it and my daughters used to love the fact that if you googled 'heroic dentist' I'd come up because of the headline used. To be honest, compared to some of the daily feats of heroism that the members of the Armed Forces perform in places like Afghanistan, it really doesn't feel special at all. The Harvey Fletcher Award is the Royal Naval Dental Services award for merit and they've only given it out five times. I was on board an aircraft carrier in Portsmouth harbour and they were doing drills with the lift that takes the aircraft out of the hanger and up on to the deck. It's this massive hydraulic structure, like a big scissor-jack and one of the female engineer mechanics got squashed as it came down. I knew the doctor was ashore and on the tanoy system we suddenly heard 'casualty, casualty, casualty' so I galloped up and got somebody to show me how to get down to her. All I really did was some airway management, with suction and oxygen and then the ambulance came and took her away and that was it. Like I said, nothing heroic really at all.

Another time I was over in Gibraltar and taking my family out on a little launch when one of our rigid inflatables came screaming back with the driver shouting 'we've got a casualty' and some poor chap had gone over the back of his yacht tender and his foot had gone through the propeller. The back of this boat was entirely awash with sea water and blood and there was a very pallid, unwell-looking man with a foot that looked more like a rack of ribs. I helped him out of the boat and on reflection I don't know how I managed to do it, but at the time I was calm. It probably tells you that I'm a jinx and all sorts of crises happen around me!

\section{What five attributes are most important to have for working within the Defence Dental Services?}

1. Willingness to embrace service culture, ethos and values

2. Willingness to work wherever you're sent

3. A 'can do' attitude

4. A commitment to continuous clinical improvement

5. Physically fit.

I'm a small cog in a big machine and you're doing the government's bidding, which I'm proud of. I'm a patriot and that's what I do.

INTERVIEW BY LAURA PACEY 